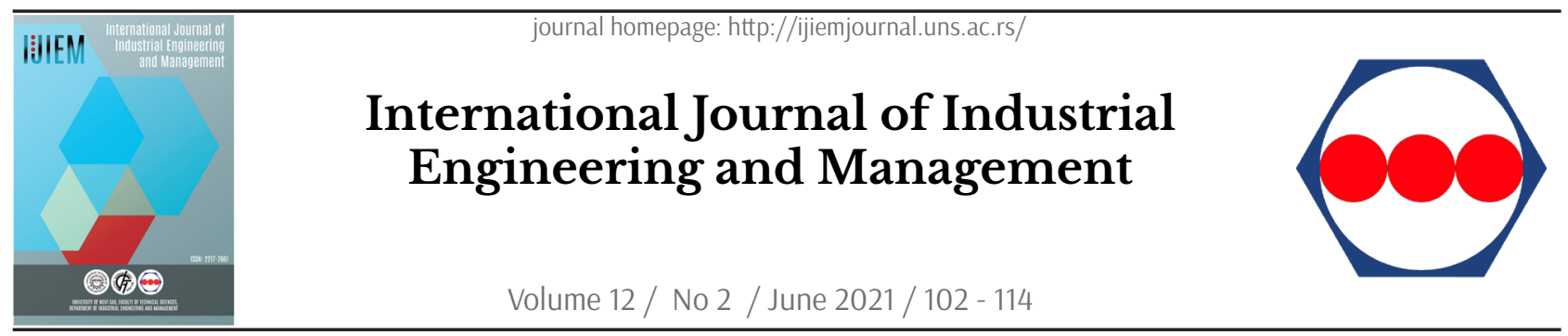

Original research article

\title{
Simulation Optimization of Manufacturing Takt Time for a Leagile Supply Chain with a De-coupling Point
}

\author{
L. N. Pattanaik \\ Department of Production Engineering, Birla Institute of Technology, Mesra, Ranchi, India
}

\begin{abstract}
A B STR A C T
Achieving agility with leanness in supply chains is considered to be a challenge for industry and academia. In order to cope with dynamic demands at extreme downstream, buffer stocks at various points on the supply chain can be seen as a solution. Although it may improve the agility feature but extra inventories at warehouses affects the leanness of the supply chain adversely. The aim of the present paper is to address this issue by finding an optimum rate of production at the factory which is directly related to Takt time concept of lean manufacturing in order to fulfill the dynamic demand patterns at the downstream retailers end while minimizing intermediate stock inventories. The model is conceived as a leagile supply chain with a de-coupling point at the warehouse or distribution center between retailers and plant. A discrete event simulation model for the supply chain is developed in WITNESS ${ }^{\circledR}$ to experiment with various rates of production before finding the optimum value. The two performance measures representing fulfillment of product demands and inventory carrying costs are expressed in equivalent cost units for optimization. Two demand scenarios for a two product supply chain are simulated to identify the optimal rate of production while illustrating the solution methodology. The simulation optimization approach to address this problem of leagile supply chain is found to be effective and practical.
\end{abstract}

\section{ARTICLE INFO}

Article history:

Received October 24, 2020

Revised April 1, 2021

Accepted April 5, 2021

Published online May 13, 2021

Keywords:

Simulation Optimization;

WITNESS $®$;

Lean Manufacturing;

Leagile Supply Chain;

Takt Time;

Decoupling point

*Corresponding author:

Laxmi Narayan Pattanaik

lnpattanaik@bitmesra.ac.in

\section{Introduction}

Supply chains often pose challenges in decision making as it involves several entities and parameters like vendors, warehouses, logistics supports, variable demands and costs, etc. Uncertainties in events and forecasted demands add more complexities to this problem. In recent times, the demand for products is highly unpredictable owing to the market dynamics and uncertainties. Further, the need of providing a wide range of product variety to cater the customized demands also aggravate the problem. In a global manufacturing environment, more and more products with shorter life cycles have been introduced to the market. In order to retain the core competence of manufacturing enterprise, its systems and supply chains should be altered in response to the changing requirement [1]. In the present dynamic world, in order to be competitive, it is integral that the customer demand be met unceasingly. The market demand is volatile because of lot of factors such as increasing demands for customization, advances in technology, seasonal variations, catastrophes, etc. It is, therefore, imperative that advancements in modeling of supply chain management systems rise up to meet the challenges [2-4].

In this context, the concepts of lean and agile supply chain models are worth a mention. Supply chain 
agility is a key to adapting to market variations more efficiently, inventory reduction, enabling firms to respond to demand more quickly and integrating with suppliers more effectively.

Lean supply chains were primarily designed for the removal of waste from all the related functions. Leanness means developing a value stream to eliminate all waste and to achieve a balanced production schedule. However, lean supply chains are considered to be attainable for relatively stable and predictable demand with low variety. On the other hand, agile supply chains provide with the solutions to problems where there is fluctuating demand with high variety. These two paradigms of lean and agile supply chains are merged to develop the conceptual model of leagile supply chain. The tradeoff between leanness and agility was balanced in a leagile supply chain system by identifying an appropriate de-coupling point [5].

De-coupling point is defined as the point where the model changes from push to pull based system. The push model works on the principle of anticipation of customer orders while pull model is executed when customer demand is known with certainty. The supply chain exhibit lean features before the decoupling point from the upstream and agility after it towards downstream. The de-coupling point is located such that it favors the need for responding to a fluctuating demand in downstream while allowing a static level of manufacturing schedule in the upstream. The decoupling point can be considered as the point where order-driven and the forecast driven functions merge [5-6].

One of the key characteristic of the lean model presented in this paper is the takt. It is a preset production rhythm associated with lean philosophy and defined as the time interval between two consecutive finished products to ensure the continual flow of finished products needed to meet customer demand. The reciprocal of production rate is mathematically equivalent to the takt time. The benefits of adopting takt during production include balanced utilization of resources, minimization of waste in finished inventory, fulfillment of demand in schedule, etc.

The aim of the present work is to find the optimum production rate or takt time of a manufacturing/assembly system associated with a leagile supply chain having stochastic and dynamic demands at multiple retailers. The objectives are to avoid excess stocks of inventory at warehouse (considered as the de-coupling point) while meeting the demands of the downstream retailers. A discrete-event simulation model is developed for the leagile supply chain to experiment with varying production rates under dynamic demand scenarios.

In section 2, literature pertaining to leagile supply chains and simulation based optimization of supply chains are compiled. The leagile supply chain model along with various assumptions, parameters and constraints, objectives for optimization are described in section 3. In section 4, experimentation with the model developed in WITNESS ${ }^{\circledR}$ is illustrated using hypothetical data sets for two stochastic demand periods, various costs, capacity of warehouse and production rates. The output from simulation model is analyzed to arrive at optimal takt or production rate for two different product types in each demand scenario. The concluding remarks and future scope of the work are presented in the last section.

\section{Literature review}

This literature review encompassed the relevant areas for the present work like agile supply chains, leanness in supply chain, leagile supply chains, de-coupling point concept, application of simulation optimization and some case studies. Literature from these areas are presented here in the same order.

Over the years it has become apparent that markets are now increasingly volatile and less predictable. So the need for a more agile response has grown. Agility is the company-wide capability that includes organizational structures, information systems, logistics, procurement and production to respond to volatility. In such market conditions of increasing levels of product variety and customization, the ability to respond to customer orders in time can provide a critical competitive advantage. Xiaomei and co-authors [7] emphasized that the traditional supply chains fail to cope up with the uncertainty in the market owing to development of economy, information technology and shortened product life cycle. Preference of customized and diversified products by end customer, uncertainties and disruptions necessitates an inherent flexibility within the supply chain network to ensure the reconfigurability; a primary requirement when developing an agile supply chain system [8-11].

Lean manufacturing concepts have been in practice over few decades and well accepted as an effective tool. The roots of lean philosophy can be traced to Toyota Production Systems (TPS) of Japan. The lean approach is applicable where there is relatively stable and predictable demand with low variety [12]. Leanness and agility, even being very different as concepts have been successfully merged within total supply chains by [5]. The combination of agility and 
leanness into supply chain with the strategic placement of a de-coupling point is termed as leagility [13]. The drawback of lean supply chain is the inability to respond to end customer customized demands, thus, leagile supply chain has been proposed in the industry to combine the advantages of both agile and lean paradigms. Compared with traditional supply chains, leagile supply chain has the advantages of information sharing, shorten length of chain, order guidance and close cooperation among stake holders.

Christopher and Towil [14] put forward the idea to bring together the lean and agile philosophies to highlight the difference in the two approaches and suggested that these can be combined for better results and advantages. The leagile supply chain focus is to effectively handle uncertain demands by deferring the products as far as possible towards the customer end. Hoek [15] highlighted benefits of the postponement strategy, like reduced inventory, increase in flexibility and multiplicity of production, easy forecasting and better personalization according to the customer demand. The importance and advantages of leagile supply chain has been discussed by a number of researchers [9] [16-17]. Ambe and Badenhorst-Weiss [18] proposed a framework for leagile supply chain appropriate for the auto industry and the implementation of which would result in cost reduction and the supply chain being more responsive. Shukla and Wan [19] in their work presented an optimization approach for a leagile inventory model. They first formulated a non-linear integer programming model which was solved in real-time using three variants of genetic algorithm. Komoto and other authors [20] in their paper on multi-objective reconfiguration method of supply chains through discrete event simulation worked on a case study to show how the multi-objective optimization has been implemented in discrete event simulation. Peirleitner et al. [21] compared two different solution methods for determining optimal parameter settings for lot size $\mathrm{Q}$ and reorder points. The first method is an analytical optimization model assuming a single-stage, single-product inventory system which is applied independently for all supply chain partners. Optimal parameters are identified for all partners and then re-evaluated in the dynamic and stochastic simulation model. Results show that if analytical optimal parameters are evaluated with simulation, which includes the dynamics and interdependencies between the supply chain members, lower service levels than initially predefined were achieved. A synchronized logistic model to address various issues of a dynamic supply chain was developed [22].

Considering supply chain as a complex and dy- namic system as compared to other analysis tools, simulation has an edge due to the dynamicity and randomness it can provide to the user. Simulation has been used for years in the areas of supply chain, manufacturing and business has led to a wide range of successful applications in different areas such as design, planning and control, strategy making, resource allocation, training, etc. [23].

Simulation is the best practice to evaluate the system performance closely to real situation. Simulation Optimization (SO) appears as popular technique and has received considerable attention from both simulation researchers and practitioners which can be achieved using software packages [24]. Ran et al. [25] presented a review on applications of $\mathrm{SO}$ to design and operation of manufacturing systems to address the inherent stochastic properties. By dividing the problems into local and global optimization category, they further classified on the basis of discrete or continuous nature. Maedeh et al. [26] solved a multi-objective problem using a hybrid of $\mathrm{SO}$ with regression analysis for unreliable and unbalanced production lines. In a recent review, classified applications of simulation optimization to supply chain problems in general with focus on resilience was found. Hybridization of $\mathrm{SO}$ with meta-heuristics was suggested as a prospective future research direction [27].

Demand uncertainty, in particular is an important factor to be considered in the supply chain design and operations. Due to advance of global manufacturing, the decentralized optimization of multi-tier supply chains for multiple retailers and manufacturers becomes more and more important. Nishi and Yoshida [28] have addressed the optimization of multi-period bi-level supply chains under demand uncertainty. The optimization algorithm to derive Stackelberg equilibrium for multi-period bi-level supply chain planning problem is developed and dealt using simulation. Matheus et al. [29] proposed a simulation based optimization approach to cope with supply chain planning and control of high uncertainty scenarios i.e. stochastic behavior and dynamic events, addressing areas of material inventory, production and transportation. In their work, they discussed a simulation based optimization approach to simultaneously deal with the planning and control of the material inventory, production and transportation areas combining the capabilities from metaheuristics and simulation models. Their proposed approach was implemented in a test case and claimed a convergence to a solution within a short span of time. Liotta et al. [30] also opine that simulation-based optimization is a strategy for dealing with uncertainty in the supply chain. In 
addition, Truong and Azadivar [31] suggested that managing a supply chain is much more complex than dealing with one facility because of existing conflicting objectives and dynamic properties of the system. Hence, they proposed a simulation-based approach to deal with supply chain configuration design.

A case study of a mobile phone manufacturing industry was undertaken. They studied mobile phone firm's operational configuration and proposed real-time decision support mechanism based on agent-based discrete-event simulation to estimate performance of average inventory levels over the system-wide supply chain [1]. Using WITNESS ${ }^{\circledR}$, a supply chain model can be built and analyzed without the need to physically carry out tests in real life [32].

In this paper, a leagile supply chain model is simulated using WITNESS ${ }^{\circledR}$ to give optimum takt times for different demand periods with conflicting objectives of minimizing stock-outs and inventory costs.

\section{Model of the leagile supply chain}

The supply chain adopted in the present paper has leagile characteristics to meet volatile market demand as well as to ensure optimum inventory level to minimize cost. To achieve this, the decoupling point is set at the warehouse which is between the production facility and the retailer(s). Products are continuously manufactured at a predetermined rate based on takt time and pushed to the warehouse after which the goods are pulled by the retailer(s) according to the customer demand. Leanness is achieved by producing the optimum amount and avoiding excess inventory and cost associated with it while agility is achieved by satisfying the customers by adjusting the takt time and reorder points according to the demands.

Takt is a pre-determined production rhythm associated with lean philosophy and defined as the time interval between two consecutive finished products needed to meet customer demand. It is expressed as the ratio between total available time for production and total customer demands during that duration. The reciprocal of production rate is mathematically equivalent to the takt time. By adopting takt during production, balanced utilization of resources, minimization of waste in finished inventory, fulfillment of demand in schedule, etc. can be achieved.

A leagile supply chain model with one manufacturer, one warehouse and six retailers (Figure 1) is presented here to illustrate the proposed simulation optimization approach. Some assumptions for the model are summarized here.

- Required inventories for production are supplied just-in-time and no shortages occur

- The manufacturer and the supply chain deals with two product varieties, product $\mathrm{A}$ and $\mathrm{B}$

- The retailers use an inventory replenishment model with re-order point and re-order quantity as parameters

- The six retailers are divided into three clusters based on their geographical locations and distances from the warehouse

The leagile supply chain model has the following parameters:

$p_{i} \quad$ Reorder point for retailer cluster $i$, in units

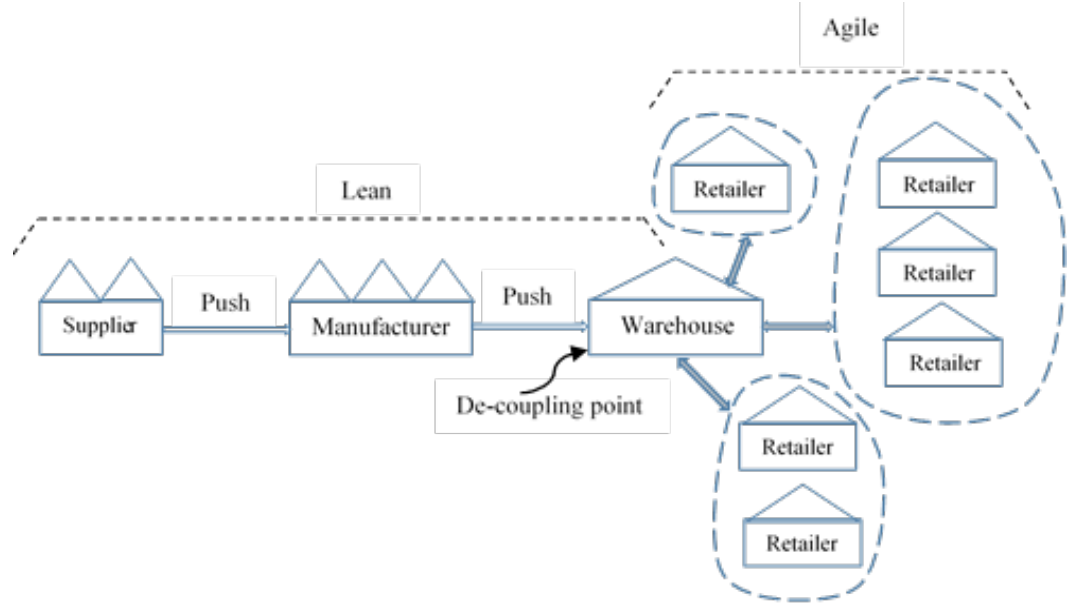

Figure 1. Model of the leagile supply chain with six retailers in three clusters 
$q \quad$ Reorder quantity, in units

$R_{i} \quad$ Retailer cluster $i$

$D_{A} \quad$ Demand for product type $A$, units/day

$D_{B} \quad$ Demand for product type $B$, units/day

$M P_{A} \quad$ Market price of product $A$ per unit

$M P_{B} \quad$ Market price of product $B$ per unit

$C P_{A} \quad$ Cost price of product $A$ per unit

$C P_{B} \quad$ Cost price of product $B$ per unit

$t_{i}$ Minimum transportation time from warehouse to retailer cluster $i$, days

$\alpha_{i} \quad$ Exponential variation in transportation time from warehouse to retailer cluster $i$, days

$T_{i} \quad$ Transportation times from warehouse to retailer cluster $i, T_{i}=\left(t_{i}+\alpha_{i}\right)$, days

$\eta_{A} \quad$ The optimum production rate of product type $\mathrm{A}$ at the plant, units/day

$\eta_{B}$ The optimum production rate of product type $\mathbf{B}$ at the plant, units/day

$\lambda_{A}$ Production capacity of the plant for product A, units/day

$\lambda_{B} \quad$ Production capacity of the plant for product B, units/day

$R_{c} \quad$ Retailer holding capacity, units

$W_{c} \quad$ Warehouse storage capacity, units

$\mathrm{y}_{i}$ Delivery capacity from warehouse to retailer cluster i, units

$T_{L} \quad$ Total loss incurred for a product, cost units

$T_{I}$ Total loss due to excess inventory at warehouse for a product, cost units

$T_{S} \quad$ Total loss due to unavailability of a product at retailers, cost units

$I_{W} \quad$ Inventory at warehouse

$I_{T} \quad$ Threshold level for inventory

The above described model is simulated to find the optimum production rate for two product types with the objective to maximize the service level (availability of products at retailers) and at the same time minimize the inventory level at the warehouse. A higher inventory level improves the service level means the customer demands are fulfilled with less stock-out situations but higher inventory can be costly for the firm as excess inventory will result in greater storage costs, risk of obsolescence, pilferage, insurance premium, etc. On the other hand lower inventory level can results in stock-outs which will impair the service levels causing loss of sales and goodwill of the customer.

In this paper a supply chain model is optimized having two conflicting objectives to maximize the service level and minimize the inventory level.

The two objectives were combined to calculate the total loss incurred due to high inventory at the warehouse and losses due to poor service level at retailers. Losses due to high inventory are considered only after the inventory level at the warehouse crosses a threshold level $I_{T}$.

$$
T_{L}=T_{S}+T_{I}
$$

Where, $T_{S}=$ (Average unfulfilled customer demand $\times$ Simulation run time $\times$ Avg. demand per day $\times$ Profit per unit) and

$T_{I}=\left\{\begin{array}{cc}0, & I_{W} \leq I_{T} \\ \left(I_{W}-I_{T}\right) \times C P, & I_{W}>I_{T}\end{array}\right.$

The takt based production rate with the lowest value of total loss $T_{L}$ gives the optimum production rate for the respective demand cycle

\section{Simulation optimization using WITNESS ${ }^{\circledR}$}

Simulation optimization is considered as an effective analytical tool to arrive at the optimal solution without implementing any classical, conventional or meta-heuristic based computation. Problems in supply chains are predominantly of combinatorial optimization types, which can be solved using simulation optimization with lesser computational complexity.

The software used in the present work, WITNESS $®$ is industry-standard simulation software with the ability to model a wide range of process and operation tasks. It is a software platform for dynamic system modeling and simulation, which is developed by the British Lanner, to cater the needs of industrial and business systems and processes (Men and Zhou, 2011). It has a wide range of application areas, a large number of model elements, a powerful simulation engine, a convenient graphical interface operation function and a hierarchical modeling function.

The leagile supply chain model is optimized using the approach of simulation optimization. Simulation optimization deals with the situation in which the analyst would like to find which of the many sets of model specifications (input parameters and/or structural 
assumptions) would lead to optimal performance. Initially, a trial model was developed in WITNESS ${ }^{\circledR}$ with single supplier, manufacturer, warehouse and a single retailer which was later expanded to the proposed model as presented in Figure 2.

WITNESS ${ }^{\circledR}$ is Lanner Group's simulation software package which provides a visual, interactive and interpretative approach to simulation without the need for compilation. The software has been adopted in discrete-event problems from various areas like automotive, pharmaceutical, aerospace, electronics, defence, services, etc. The WITNESS ${ }^{\circledR}$ Manufacturing Performance Edition has been specially designed for manufacturing applications. It is ideally suited to a variety of production and storage layout, logistical modelling and supply chain modelling scenarios.

\subsection{Experimentation with simulation model}

For experimentation on the constructed model of the leagile supply chain, two product types A and B are considered where $\mathrm{A}$ is cheaper and of higher demand than B. When the stock with the retailer drops below the reorder point $\mathrm{p}$ units, the retailer places an order of reorder quantity q to the warehouse. The warehouse receives the order and forwards to 'Picking' where the orders are dispatched to the retailer via delivery.

The model was simulated for 1000 days with 250 days as warm-up period and the statistics of the inventory accumulated at the warehouse and the unfulfilled customer demand percentage at each retailer were found. The unfulfilled customer demand percentage is a direct indication of service level.

Service level $\%=(1-$-unfulfilled customer demand \%)
The simulation model was run for two hypothetical demand cycles to understand the behavior of the supply chain under volatile demand conditions. Referring to the notations for various parameters and variables as expressed in section 3 , the numerical input data used for the model are as follows:

$$
\begin{array}{lll}
\lambda_{B} & 30-60 \text { units/day } & \alpha_{1} \operatorname{Exp}(0.125) \text { days } \\
R_{c} & 1000 \text { units } & \alpha_{2} \operatorname{Exp}(0.25) \text { days } \\
W_{c} & 6000 \text { units } & \alpha_{3} \operatorname{Exp}(1.0) \text { days } \\
\text { У1 } & 30 \text { units } & \mathrm{t}_{3} \quad 4.0 \text { days } \\
\text { 82 } & 55 \text { units } & C P_{A} 100 \text { cost units } \\
\text { 83 } & 75 \text { units } & M P_{A} 160 \text { cost units } \\
\mathrm{t}_{1} & 0.5 \text { days } & C P_{B} \quad 150 \text { cost units } \\
\mathrm{t}_{2} & 1.0 \text { days } & M P_{B} \quad 250 \text { cost units } \\
I_{T} & 500 \text { units } \\
C a s e & \text { (i) First demand cycle } \\
D_{A}: & \text { Uniform distribution }[5,10] \text { units/day } \\
D_{B}: & \text { Uniform distribution }[5,7] \text { units/day } \\
p_{1}= & 5 \text { units } \\
p_{2}= & 10 \text { units } \\
p_{3}= & 50 \text { units }
\end{array}
$$

The demand is taken to be uniformly distributed integer values between the upper and lower bound values. The model was run for different production rates within the plant capacity ranges $\lambda_{A}$ and $\lambda_{B}$. The results for average unfulfilled customer demand percentage of all the retailers and the inventory accumulated in the warehouse were found for products $\mathrm{A}$ and product $\mathrm{B}$ as produced in Table 1 .

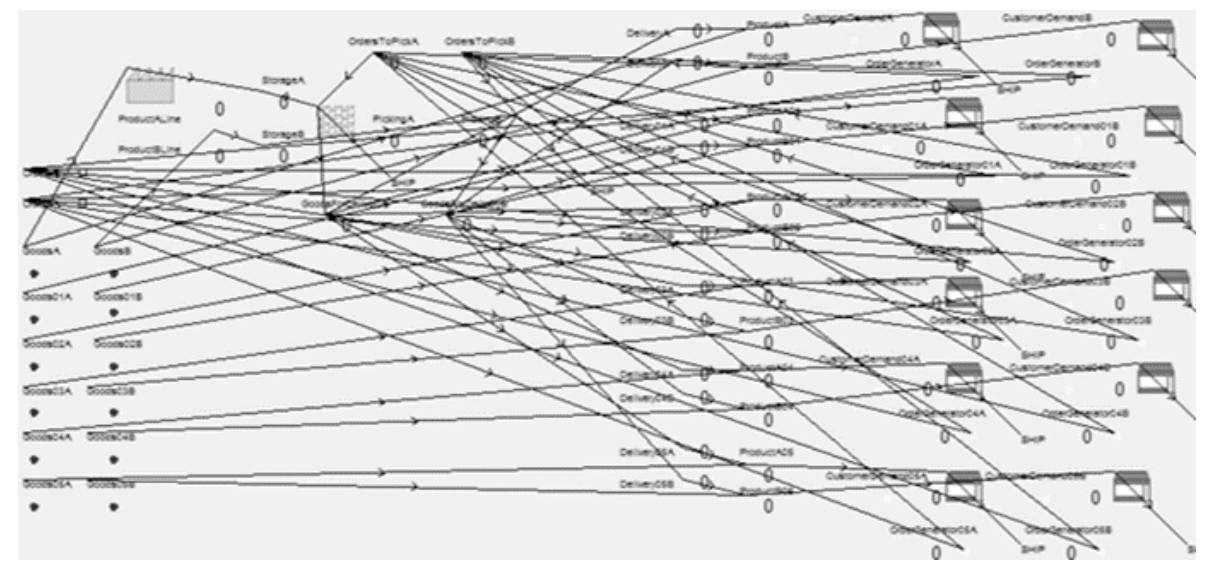

Figure 2. Screen print of the leagile supply chain in WITNESS ${ }^{\circledR}$ 
The losses due to poor service level at retailer end and high inventory at warehouse are calculated by using Eq. (1) and (2). An example is given here to explain the calculation of total loss.

Production rate $($ Product $\mathrm{A})=40$ units/day

Unfulfilled customer demand $=7.17 \%$

Inventory level at warehouse $=40$

Simulation run time $=1000$ days

Average demand per day $=7.5$ units/day

Profit for product $\mathrm{A}=60 /$ unit
Referring to (1) and (2),

$$
\begin{aligned}
& T_{S}=(7.17 / 100) \times 1000 \times 7.5 \times 60=32257.5 \\
& T_{I}=0 \text { since } I_{W} \leq I_{T}(\because 40<500) \\
& T_{L}=T_{S}+T_{I}=32257.5+0=32257.5
\end{aligned}
$$

Similarly, the total loss $T_{L}$ is calculated for all other production rates for product $\mathrm{A}$ and product $\mathrm{B}$ as given in Table 2.

Table 1. Simulation results of the first demand cycle

\begin{tabular}{|c|c|c|c|c|c|c|c|}
\hline \multicolumn{4}{|c|}{ Product A } & \multicolumn{4}{|c|}{ Product B } \\
\hline $\begin{array}{l}\text { Production } \\
\text { rate }\end{array}$ & $\mathrm{T}_{\mathrm{S}}$ & $\mathrm{T}_{\mathrm{I}}$ & Total Loss & Production rate & $\mathrm{T}_{\mathrm{S}}$ & $\mathrm{T}_{\mathrm{I}}$ & Total Loss \\
\hline 40 & 32257.5 & 0 & 32257.5 & 30 & 65180 & 0 & 65180 \\
\hline 41 & 23932.5 & 0 & 23932.5 & 32 & 48810 & 0 & 48810 \\
\hline 42 & 17010 & 0 & 17010 & 34 & 23680 & 0 & 23680 \\
\hline 43 & 11122.5 & 0 & 11122.5 & 35 & 11180 & 0 & 11180 \\
\hline 44 & 9517.5 & 5000 & 14517.5 & 36 & 5170 & 0 & 5170 \\
\hline 45 & 8490 & 108000 & 116490 & 37 & 5940 & 213000 & 218940 \\
\hline 48 & 5992.5 & 450000 & 455992.5 & 38 & 4390 & 367500 & 371890 \\
\hline 49 & 6952.5 & 550000 & 556952.5 & 39 & 5170 & 555000 & 560170 \\
\hline 50 & 6540 & 547000 & 553540 & 40 & 5100 & 742500 & 747600 \\
\hline
\end{tabular}

\begin{tabular}{llllll}
\hline & \multicolumn{2}{c}{ Product A } & \multicolumn{2}{c}{ Product B } \\
\hline $\begin{array}{l}\text { Production } \\
\text { rate }\end{array}$ & $\begin{array}{c}\text { Ave. \% unfulfilled } \\
\text { customer demand }\end{array}$ & $\begin{array}{c}\text { Inventory at } \\
\text { warehouse }\end{array}$ & Production rate & $\begin{array}{c}\text { Ave. \% unfulfilled } \\
\text { customer demand }\end{array}$ & $\begin{array}{c}\text { Inventory at } \\
\text { warehouse }\end{array}$ \\
\hline 40 & 7.17 & 40 & 30 & 10.86 & 0 \\
41 & 5.32 & 41 & 32 & 8.14 & 0 \\
42 & 3.78 & 42 & 34 & 3.95 & 34 \\
43 & 2.47 & 43 & 35 & 1.86 & 35 \\
44 & 2.12 & 550 & 36 & 0.86 & 450 \\
45 & 1.89 & 1580 & 37 & 0.99 & 1920 \\
48 & 1.33 & 5000 & 38 & 0.73 & 2950 \\
49 & 1.55 & 6000 & 39 & 0.86 & 4200 \\
50 & 1.45 & 5970 & 40 & 0.85 & 5450 \\
\hline
\end{tabular}

Table 2. Total losses for products at various production rates in first demand cycle 
In Figure 3, the trade-off between average percentage customer unfulfilled demand and inventory level at warehouses can be clearly observed. In order to reduce the unfulfilled customer demand, higher inventory stocks at warehouses and retailers are required which again leads to the disadvantages of carrying extra inventory.

The data for product A from Table 2 are plotted in Figure 4 to find the optimum production rate of 43 units/day (highlighted in a circle) that gives the desired objective of minimum total loss.

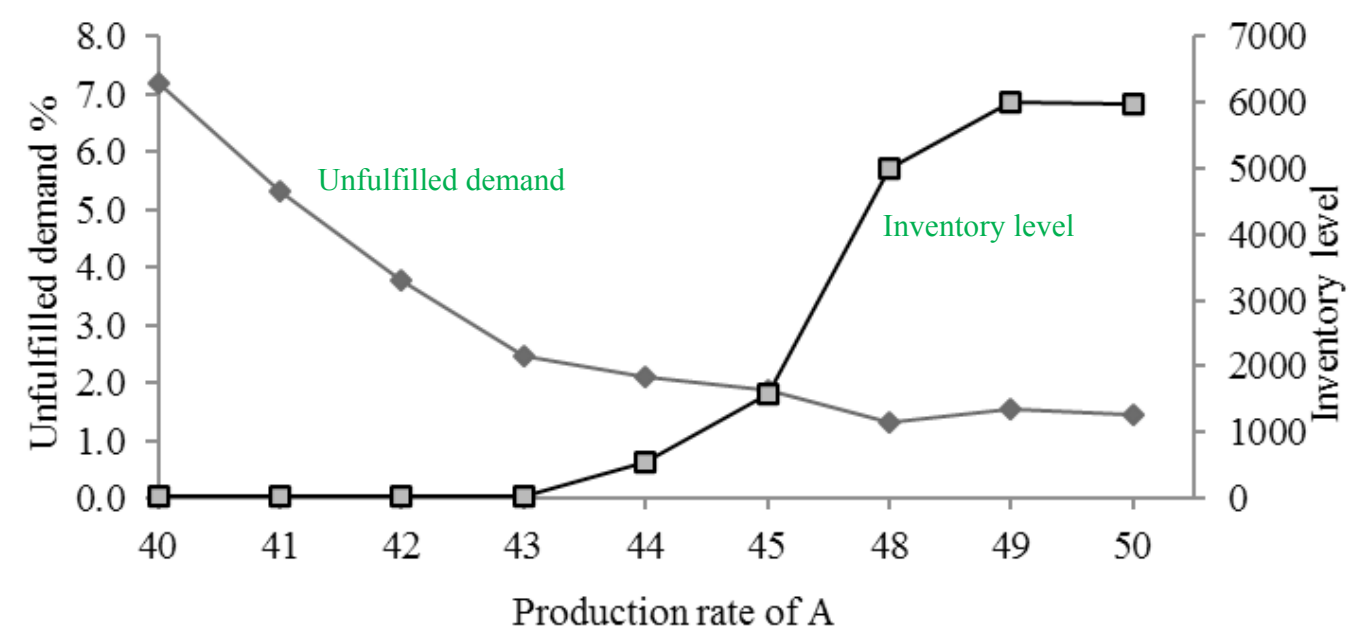

Figure 3. Variation in unfulfilled demand and inventory level with production rate of A

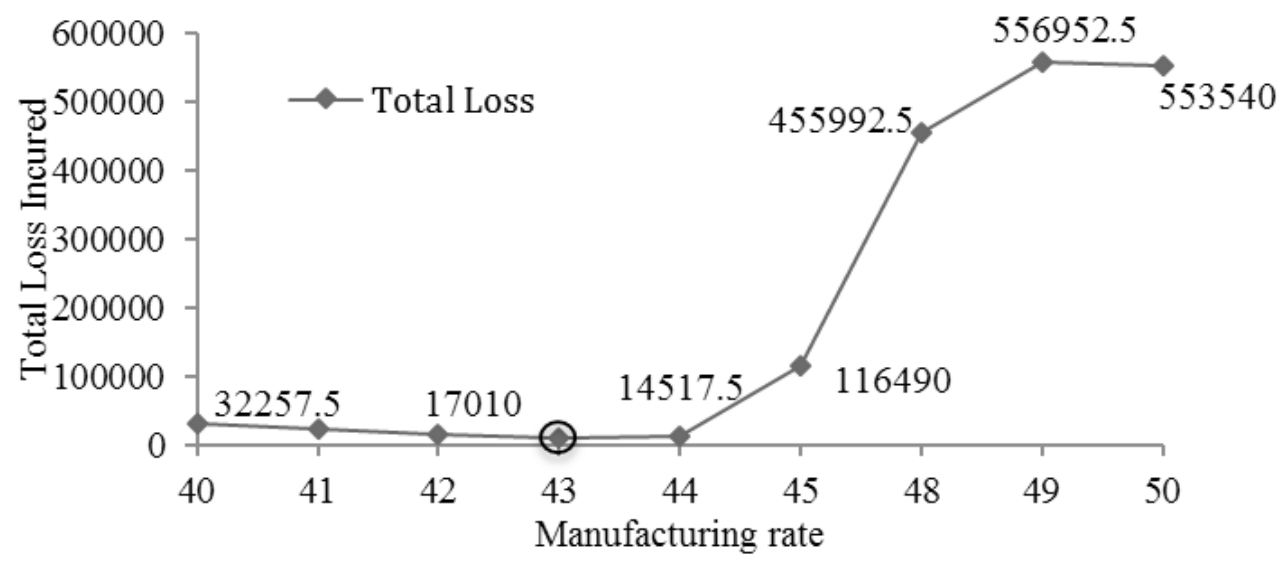

Figure 4. Variation in total loss with production rate for product $A$

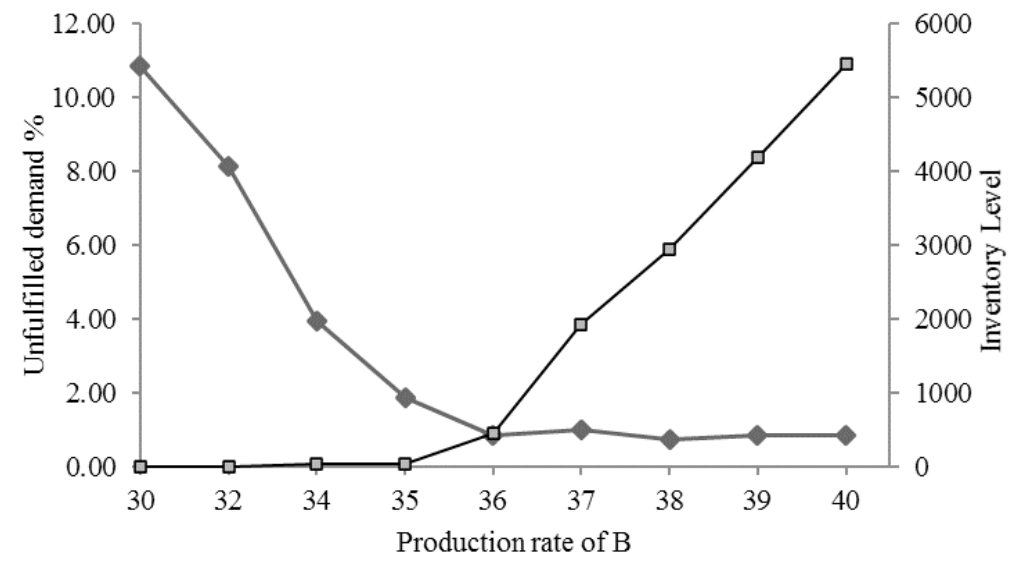

Figure 5. Variation in unfulfilled demand and inventory level with production rate of B 
Similar to the Figure 3 (for Product A), Figure 5 indicates the same variation and trade-off relation between unfulfilled demand and inventory level of product $\mathrm{B}$.

Figure 6 shows the optimum production rate for product $\mathrm{B}$ as 36 units/day where the total loss incurred is minimum.

Case (ii) Second demand cycle

$D_{A}$ : Uniform distribution [10,15] units/day

$D_{B}:$ Uniform distribution $[7,10]$ units/day

$p_{1}=5$ units

$$
\begin{aligned}
& p_{2}=10 \text { units } \\
& p_{3}=50 \text { units }
\end{aligned}
$$

The data for average unfulfilled customer demand percentage of all the retailers and the inventory accumulated at the warehouse was collected for product A and product B separately as presented in Table 3.

Here, it can be seen that the average unfulfilled customer demand percentage for product A is very high and is not satisfying a service level of at least $95 \%$. The reason is that the re-order point, pi being too low. The re-order point of the retailer needs to be heightened as the demand increases. After recog-

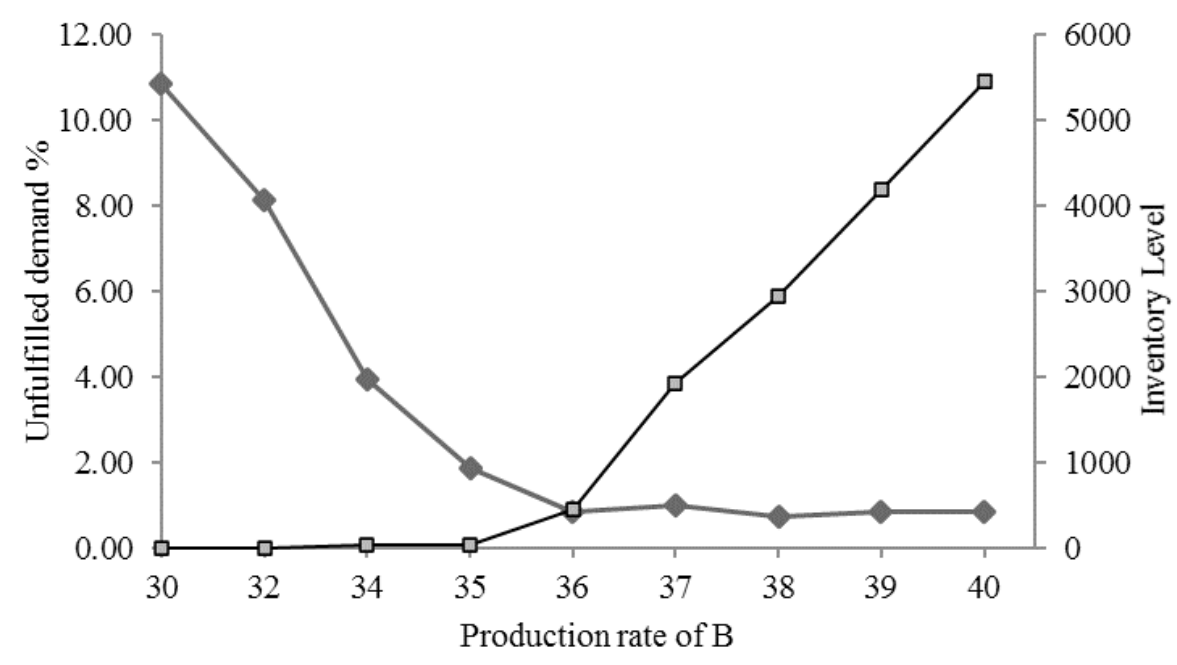

Figure 6. Variation in total loss for product B

Table 3. Simulation results of the second demand cycle

\begin{tabular}{lccccc}
\hline & \multicolumn{2}{c}{ Product A } & \multicolumn{2}{c}{ Product B } \\
\hline $\begin{array}{l}\text { Production } \\
\text { rate }\end{array}$ & $\begin{array}{c}\text { Ave. unfulfilled } \\
\text { customer demand \% }\end{array}$ & $\begin{array}{c}\text { Inventory at } \\
\text { warehouse }\end{array}$ & Production rate & $\begin{array}{c}\text { Ave. unfulfilled } \\
\text { customer demand \% }\end{array}$ & $\begin{array}{c}\text { Inventory at } \\
\text { warehouse }\end{array}$ \\
\hline 60 & 11.12 & 90 & 45 & 7.15 & 45 \\
65 & 7.63 & 70 & 48 & 3.76 & 270 \\
67 & 6.81 & 1910 & 49 & 3.94 & 1740 \\
68 & 6.51 & 2720 & 50 & 3.91 & 2660 \\
69 & 7.56 & 4740 & 51 & 3.98 & 4240 \\
70 & 7.68 & 5870 & 52 & 4.61 & 5600 \\
72 & 6.94 & 6000 & 55 & 4.42 & 5995 \\
75 & 6.83 & 5835 & 60 & 4.48 & 5930 \\
\hline
\end{tabular}


nizing this, the model was simulated by enhancing the re-order points as below.

$$
\begin{aligned}
& p_{1}=10 \text { units } \\
& p_{2}=20 \text { units } \\
& p_{3}=80 \text { units }
\end{aligned}
$$

The simulation results for the revised model are given in Table 4.

Total loss $T_{L}$ is calculated for both the products at all the levels of production rates as produced in Table 5 . The corresponding data is shown below in Table 10.

The data from Table 5 are plotted to mark the optimum production rate for products $\mathrm{A}$ and $\mathrm{B}$ in Figures 7 and 8 respectively. The optimum production rates for the products $\mathrm{A}$ and $\mathrm{B}$ are 69 and 49 units/day as highlighted in circles.

Table 4. Simulation results of the second demand cycle with revised re-order points

\begin{tabular}{llcccc}
\hline & \multicolumn{2}{c}{ Product A } & \multicolumn{2}{c}{ Product B } \\
\hline $\begin{array}{l}\text { Production } \\
\text { rate }\end{array}$ & $\begin{array}{c}\text { Ave. unfulfilled } \\
\text { customer demand } \%\end{array}$ & $\begin{array}{c}\text { Inventory at } \\
\text { warehouse }\end{array}$ & Production rate & $\begin{array}{c}\text { Ave. unfulfilled } \\
\text { customer demand } \%\end{array}$ & $\begin{array}{c}\text { Inventory at } \\
\text { warehouse }\end{array}$ \\
\hline 60 & 10.78 & 60 & 45 & 7.83 & 45 \\
65 & 6.89 & 65 & 48 & 2.91 & 48 \\
67 & 5.36 & 150 & 49 & 1.86 & 200 \\
68 & 4.47 & 68 & 50 & 1.85 & 790 \\
69 & 3.73 & 340 & 51 & 2.36 & 2480 \\
70 & 4.31 & 1040 & 52 & 2.48 & 3840 \\
72 & 3.63 & 3430 & 55 & 2.78 & 5775 \\
\hline
\end{tabular}

Table 5. Total losses for products at various production rates in second demand cycle

\begin{tabular}{cccccccc}
\hline \multicolumn{2}{c}{ Product A } & \multicolumn{5}{c}{ Product B } \\
\hline $\begin{array}{c}\text { Production } \\
\text { rate }\end{array}$ & $\mathrm{T}_{\mathrm{S}}$ & $\mathrm{T}_{\mathrm{I}}$ & Total Loss & Production rate & $\mathrm{T}_{\mathrm{S}}$ & $\mathrm{T}_{\mathrm{I}}$ & Total Loss \\
\hline 60 & 80825 & 0 & 80825 & 45 & 66526.6 & 0 & 66526.6 \\
65 & 51662.5 & 0 & 51662.5 & 48 & 24692.5 & 0 & 24692.5 \\
67 & 40187.5 & 0 & 40187.5 & 49 & 15795.8 & 0 & 15795.8 \\
68 & 33550 & 0 & 33550 & 50 & 15753.3 & 43500 & 59253.3 \\
69 & 27987.5 & 0 & 27987.5 & 51 & 20074.1 & 297000 & 317074.1 \\
70 & 32287.5 & 54000 & 86287.5 & 52 & 21108.3 & 501000 & 522108.3 \\
72 & 27212.5 & 293000 & 320212.5 & 55 & 23601.6 & 791250 & 814851.6 \\
75 & 32625 & 520500 & 553125 & 60 & 20003.3 & 816000 & 836003.3 \\
\hline
\end{tabular}




\section{Conclusion}

In the present paper, a trade-off problem identified between inventory cost and shortage cost in a leagile supply chain. The two conflicting objectives were maximization of service level at the retailer end and minimization of inventory at the warehouse, the decoupling point. A simulation optimization approach implemented using WITNESS ${ }^{\circledR}$ simulation software to find the optimal rate of production for lean portion of the supply chain. Similar to the takt time concept of lean manufacturing, the optimal production rate is capable of meeting customer demands as pulled from the downstream retailers as well as minimize the inventory carrying cost at the warehouse or distribution center. To implement leagile supply chain, different demand cycles were considered to understand how the model can respond to changes in the market demand. The data for two hypothetical demand cycles were generated using ran-

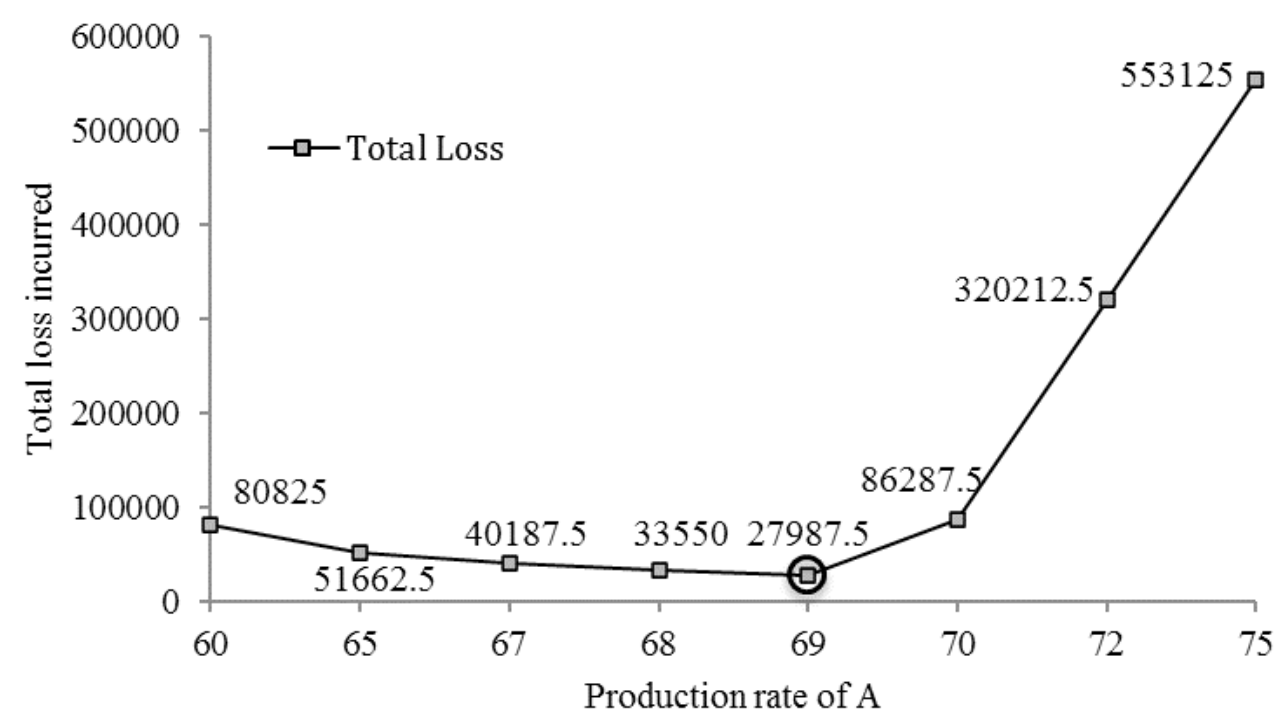

Figure 7. Variation in total loss for product $A$ in second demand cycle

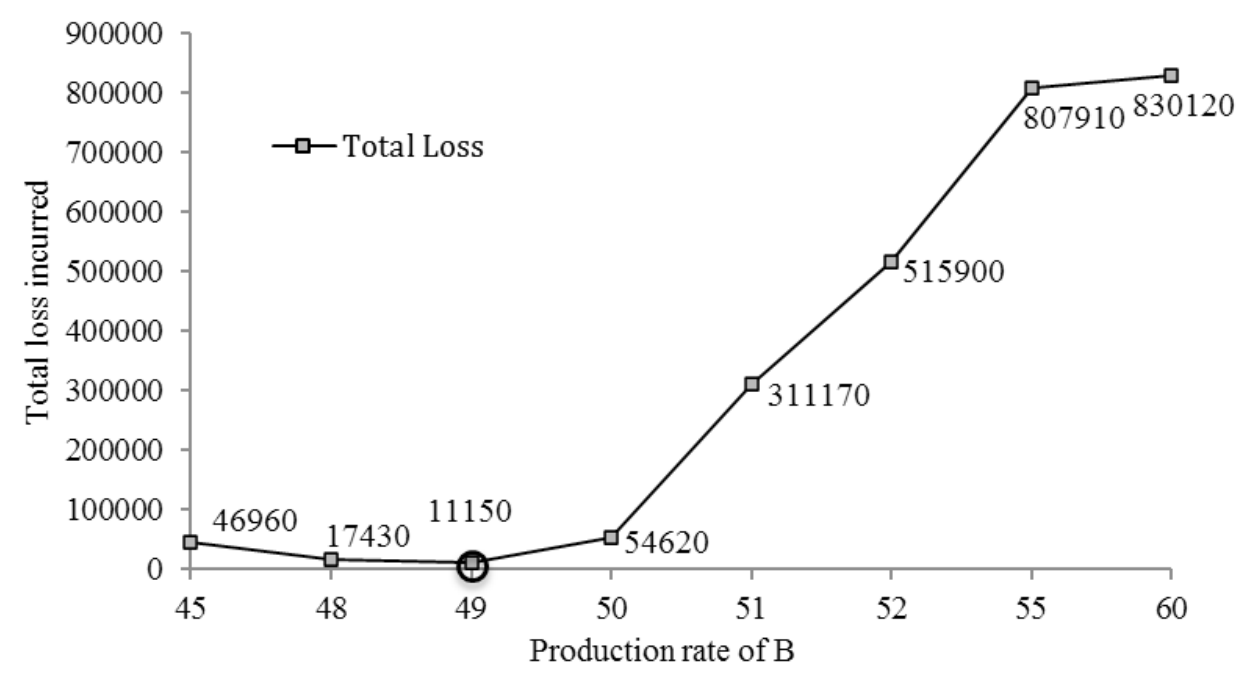

Figure 8. Variation in total loss for product B in second demand cycle 
dom distributions to run the simulation model for two product types. The bi-objective function outputs were transformed into the same cost units for ease of comparison and analysis.

An adequate mean service level of $95 \%$ and above was reached while minimizing inventory costs for the two demand scenarios. The optimal rate of production for the two products in two different demand cycles was found. It was also established a fact that the re-order point plays a key role as the demand fluctuates. The retailer must increase its re-order point to meet the increasing customer demand.

Application of simulation optimization approach to a leagile supply chain to find optimum production rate is a novel exploration which this paper reported. As a future scope of the present work, the model could be expanded by adding multiple manufacturing plants and warehouses at different geographical locations to represent typical automobile firms. The effects of several other parameters like location of de-coupling point, truckload capacity, re-order quantity, etc. can also be studied on the unfulfilled demands and inventory levels.

\section{Acknowledgements}

The author wish to thank the two anonymous reviewers for their valued review and suggestions to improve the content and presentation of the paper.

\section{Funding}

This research did not receive any specific grant from funding agencies in the public, commercial, or not-for-profit sectors.

\section{References}

[1] Dev, N. K., Ravi Shankar, Angappa Gunasekaran, Lakshman S. Thakur, 2016. A hybrid adaptive decision system for supply chain Reconfiguration. Int. J. Prod. Res. 54(23), 7100-7114.

[2] Naim, M. M., Gosling, J., 2011. On leanness, agility and leagile supply chains. Int. J. Prod. Econ. 131(1), 342-354.

[3] Chatterjee, P. and Stevi, ․ 2019. A two-phase fuzzy AHP-fuzzy TOPSIS model for supplier evaluation in manufacturing environment. Operational Research in Engineering Sciences: Theory and Applications, 2(1), 72-90.

[4] Klochkov, Y., Gazizulina, A., and Muralidharan, K. (2019). Lean six sigma for sustainable business practices: A case study and standardization. International Journal for Quality Research, 13(1), 47-74.

[5] Rachel Mason-Jones, Ben Naylor, Denis, R. Towill, 2000. Lean, agile or leagile? Matching your supply chain to the marketplace. Int. J. Prod. Res. 38(17), 4061-4070.

[6] Prince, J., Kay, J. M., 2003. Combining lean and agile char acteristics: Creation of virtual groups by enhanced production flow analysis. Int. J. Prod. Econ. 85(3), 305-318.

[7] Xiaomei, Li, Zhaofang, Mao, Guohong, Xia, Fu Jia, 2008. Study on manufacturing supply chain leagile strategy driven factors based on customer value, 4th International Conference on Wireless Communications, Networking and Mobile Computing, Dalian, China DOI: $10.1109 / \mathrm{WiCom} .2008 .1642$

[8] Dev, N. K., Ravi Shankar, Prasanta Kumar Dey, 2014. Re configuration of supply chain network: an ISM-based roadmap to performance. Benchmarking: An International Journal. 21(3), 386-411.

[9] Purvis, L., Gosling, J., Naim, M. M., 2014. The development of a lean, agile and leagile supply network taxonomy based on differing types of flexibility. Int. J. Prod. Econ. 151, 100-111.

[10] Shashi, Piera Centobelli, Roberto Cerchione and Myriam Ertz, 2020. Agile supply chain management: where did it come from and where will it go in the era of digital transformation?, Industrial Marketing Management, 90, 324-345.

[11] Mansoor Shekarian, Seyed Vahid, Reza Nooraie and Mahour Mellat Parast, 2020. An examination of the impact of flexibility and agility on mitigating supply chain disruptions, International Journal of Production Economics, 220, 107438.

[12] Yuik, C. Jia and P. Puvanasvaran. 2020. Development of Lean Manufacturing Implementation Framework in Machinery and Equipment SMEs. Int. J. Ind. Eng. Manag., 11(3), 157-169.

[13] Naylor, J. B., Mohamed M Naim, Danny Berry, 1999. Leagility: Integrating the lean and agile manufacturing paradigms in the total supply chain. Int. J. Prod. Econ. 62, 107-118.

[14] Christopher, M., Towill, D., 2001. An integrated model for the design of agile supply chains. Int. J. Phys. Distr. Log. 31(4), 235-246.

[15] Hoek, R. V., 1998. Reconfiguring the supply chain to implement postponed manufacturing. Int. J. Logist. Manag. 9(1), 95-110.

[16] Rahiminezhad Galankashi, M., Helmi, S.A. 2016. Assessment of hybrid Lean-Agile (Leagile) supply chain strategies, J. of Manuf. Tech. Manage. 27(4), 470-482.

[17] Huang, Y. Y., Li, S. J., 2010. How to achieve leagility: a case study of a personal computer original equipment manufacturer in Taiwan. J. Manuf. Syst. 29(2-3), 63-70.

[18] Ambe, I. M., J. A. Badenhorst-Weiss, 2010. Strategic supply chain framework for the automotive Industry. Afr. J. Bus. Manage. 4(10), 2110-2120.

[19] Shukla, S. K., Wan, H. D., 2010. A leagile inventorylocation model: formulation and its optimisation. Int. J. Oper. Res. 8 (2), 150-173.

[20] Komoto, H., T. Tomiyama, M. Nagel, S. Silvester, H. Brezet, 2005. A multi-objective reconfiguration method of supply chains through discrete event simulation, 4th Inter national Symposium on Environmentally Conscious Design and Inverse Manufacturing, Tokyo, Japan. DOI: 10.1109/ECODIM.2005.1619238

[21] Peirleitner, A. J., Thomas F., Klaus, A., 2016. A simulation approach for multi-stage supply chain optimization to analyze real world transportation effects. Proceedings of the Winter Simulation Conference (WSC), Washington, DC, USA. DOI: 10.1109/WSC.2016.7822268

[22] Diamantino Torres, Ana Raquel Xambre and Leonor Teixeira, 2016. Development of Synchronized Logistics Scenarios, Int. J. Ind. Eng. Manag., 7(2), 85-94.

[23] Mohsen, J., Tillal, E., Aisha, N., Lampros, K. S., Terry, Y., 2010. Simulation in manufacturing and business: A review. Eur. J. Oper. Res. 203(1), 1-13. 
[24] Othman, S., Noorfa, H., 2012. Supply chain simulation and optimization methods: an overview, 3rd International Conference on Intelligent Systems Modelling and Simulation, Kota Kinabalu, Malaysia, DOI: 10.1109/ISMS.2012.122

[25] Ran Liu, Xiaolei Xie, Kaiye Yu, Qiaoyu Hu, 2018. A survey on simulation optimization for the manufacturing system operation, Int. J. of Mod. Sim. 38 (2), 116-127.

[26] Maedeh Mosayeb Motlagh, Parham Azimi, Maghsoud Amiri, Golshan Madraki, 2019. An efficient simulation optimization methodology to solve a multi-objective problem in unreliable unbalanced production lines, Expert Systems With Applications, 138, 112836.

[27] Rafael D. Tordecilla, Angel A. Juan, Jairo R. MontoyaTorres, Carlos L. Quintero-Araujo, Javier Panadero, 2021. Simulation-optimization methods for designing and assessing resilient supply chain networks under uncertainty scenarios: A review, Simulation Modelling Practice and Theory, 106, 102166.

[28] Nishi, T., Yoshida, O., 2016. Optimization of multiperiod bi-level supply chains under demand uncertainty. Procedia CIRP, 41, 508-513.

[29] Matheus, C. P., Enzo, M. F., Apolo, M. C. D., Mirko, K., Michael, F., 2018. Towards a simulation-based optimization approach to integrate supply chain planning and control, 51 st CIRP Conference on Manufacturing Systems, Procedia CIRP. 72, 520-525.

[30] Liotta, G., Kaihara, T., and Stecca, G., 2016. Optimization and simulation of collaborative networks for sustainable production and transportation. IEEE T. Ind. Inform. 12(1), 417-424.

[31] Truong, T. H., Azadivar, F., 2003. Simulation based optimization for supply chain configuration design. Proceedings of the Winter Simulation Conference, New Orleans, LA, USA, DOI: 10.1109/WSC.2003.1261560

[32] Ong, J. Q., Latif, M., Kundu, S., Tyagi, G. K., Sehgal, P., 2014. Exploiting WITNESS simulation for SCM. Int. J. of Res. Manage. Sc. Tech. 2(2), 103-109. 